\title{
EARTHQUAKE RESISTANT DESIGN OF FOUNDATIONS
}

\author{
M. J. Pender ${ }^{1}$
}

\author{
This paper was presented as one of the keynote addresses at the Pacific Conference on Earthquake Engineering,
} PCEE 95. Melbourne, November 1995

\begin{abstract}
SUMMARY
This paper reviews the main issues to be addressed in the design of shallow and deep foundations which may be subject to earthquake loading. Information is presented on the soil properties required as well as the various design analysis techniques with a view to assessing the current stateof-the-art and highlighting areas in which further techniques need to be developed. The paper sets out, by way of an overview, a sequence of steps that a designer may follow in developing a foundation system. It is concluded that, at present, the greatest deficiencies lie in the areas of most potential use to designers. A secondary aim of the paper is to enhance communication between geotechnical and structural engineers on aseismic foundation design.
\end{abstract}

\section{INTRODUCTION}

The intention of this keynote paper is to review the current stateof-the-art of the aseismic design of foundations. It is written with a general, rather than specialised geotechnical, audience in mind. The aim is to highlight those areas for which design methods, as distinct from methods of analysis, are in need of development. Places in the text where these topics are mentioned are marked at the end of the relevant sentence(s) with the symbol: (2)).

Aseismic foundation design cannot be isolated from structural design as important soil-structure interaction questions must be considered. Something of a quandary confronts the designer as structural behaviour can be specified with considerable precision, whereas geotechnical considerations are so often clouded by uncertainties in soil behaviour and properties. The design concepts set out in this paper are presented with these difficulties in mind and are intended to stimulate foundation design processes based on the real behaviour of soil during earthquake loading.

The main criteria for successful foundation performance under earthquake loading are similar to those for static loading and centre around capacity and acceptable deformations. However, the relative infrequency and brief duration of earthquake loading mean that, in comparison with static loads, it is possible to tolerate the mobilisation of a larger proportion of the foundation capacity and possibly some inelastic deformation.

The paper reviews briefly the nature of the design process and introduces the term design analysis to cover the analytical or computational phase of the process. In the space available the general steps of the design process and the type of knowledge required are reviewed.
Where possible recommended methods are supported by reference to specific instances of the observed performance of foundations, or data obtained from prototype or near prototype field tests, or information gleaned from centrifuge and shaking table tests.

\section{GEOTECHNICAL DESIGN PROCESS}

To reach a satisfactory solution to a geotechnical problem regardless of whether we are dealing with aseismic foundation design, or the design of a foundation for static, wind, or wave loading - information is needed under the following headings:

(i) We need to know about the geological environment of the site, the processes leading to the formation of the soils present, and the stratigraphy as well as variations thereof with depth and position across the site. This understanding requires input from engineering geology, information about adjacent sites, and site investigation. Eventually the information gathered, when supplemented with soil property data (obtained in step three below), will be synthesised into a geotechnical model of the site.

(ii) In addition we require details of the loads that will be applied to the foundation soil by the facility to be constructed and information about the required performance. Loads and load factors are specified in loadings standards (for example the NZ Loadings Standard NZS 4203:1992 [94], the Australian Loading Code AS1170.4:1993 [93], Eurocode 1 [12], or the Uniform Building Code [35]). Generally a higher mobilisation of the system capacity is accepted for earthquake loading. Performance criteria, usually stability and deformation limits, are iikely to be set during the initial stages of a design or specified as part of the design brief. 
(iii) Having an understanding of the site, the loads that will be applied, and the performance requirements of the proposed facility, values need to be estimated for the soil parameters which are of importance. This can be done with traditional sampling and laboratory testing, but correlations based on penetrometer results are likely to be a more direct source of preliminary design information as are in situ test results and information derived from nearby sites with similar geology.

(iv) The next step is to investigate possible solutions to the problem in hand and estimate the performance of the various options. This involves, among other things, calculations of load capacity, assessment of factors of safety or other measures of reliability, and estimates of deformation under the expected loads. This process will be referred to herein as design analysis; it is discussed below.

(v) A further stage in arriving at a solution is to consider methods of construction and related processes such as ground improvement

(vi) Constraints that need to be satisfied (usually finance and time) must be considered in the design process. This often means that a solution must be reached without all the data that would be regarded as necessary in an ideal world.

(vii) The final step of the problem solving process is the exercise of judgement which often requires an assessment of risk.

What we are involved with here is a design process; design in the widest sense embracing initial conception, investigation, idealisation of the soil profile, design analysis, detailed design, and development of a means of construction. This is a very broad activity requiring the synthesis of insight, creativity, technical knowledge, and experience. The problem solving process is presented above as a sequence. In reality it is more likely to be cyclic with several passes through the steps outlined (and perhaps others). A central difficulty is obtaining adequate information about the soil conditions and properties. One additional step, intended to overcome some of the difficulties of site investigation, may be the application of the observational method, Peck [73], to confirm, modify, or improve design decisions during construction.

Design for earthquake loading is one facet of the wider foundation design process outlined above. Apart from the requirements for the fourdation to have adequate capacity and acceptable deformation, the designer must address the changes that the earthquake induces in the soil profile. Among these are the generation of excess pore water pressures, leading to liquefaction, and post-earthquake settlement.

\section{SITE INVESTIGATION}

In essence what is needed for foundation design is information about the local geology, soil layering and soil type, and the depth to rock. It is of particular importance to note any abrupt contrast in properties between soil layers and underlying rock or even sharp changes between adjacent soil layers. This needs to be followed by information about the soil strength and stiffness; for aseismic design these are usually undrained properties.
A good indication of soil types and properties can be obtained from a penetration test. The two commonly used versions of these are the Standard Penetration Test (SPT) and the Cone Penetration Test (CPT). The SPT is able to penetrate stronger soils than the CPT but does not give the continuous record of penetration resistance, which makes it possible to identify thin layers, nor measure the sleeve resistance, which enables soil classification. Further, the CPT device is capable of taking additional instrumentation which can enhance the information obtained.

The strength of the soils penetrated, undrained shear strength for clays and friction angle for sands, can be estimated with correlations based on penetration resistance. In addition correlations exist between penetration resistance and the shear wave velocity (and hence the small strain stiffness) of soils Although this is indirect, it has the advantage that the complications of sample retrieval and disturbance do not arise. In recent years there has been much work on penetration techniques, interpretation, and the development of correlations. This can be expected to continue and reflects the popularity of the penetrometer over more sophisticated in situ testing devices. A very extensive source of correlations is the report by Kulhawy and Mayne [45]. A word of caution: correlations should be validated before being relied on as in many cases the origin of the correlation is a different soil type on another continent. Another warning relates to the use of correlations based on the SPT; one needs to be aware that practice varies from one country to another and so the standard energy may not be delivered to the penetrometer.

More sophisticated in situ testing revolves around the use of pressuremeters, Clark [16], and geophysical methods, the current state of which is summarised in the volume edited by Woods [103]

A site investigation might make several penetration soundings and back these up with a smaller number of "calibration" boreholes from which samples are recovered. When cohesive soils are present the standard classification tests give the liquidity index from which the expected behaviour of soil can be inferred and against which data from sophisticated laboratory testing can be gauged. With good quality sampling techniques it is possible to obtain the dynamic properties for clay from cyclic testing in the laboratory, although one needs to be aware that the small strain shear modulus is sensitive to even small amounts of disturbance (discussed further below). In the case of cohesionless soils successful undisturbed sampling is very difficult. Japanese workers have overcome some of these problems with in situ freezing prior to sampling, Yoshimi et al [117]. The samples are kept frozen during transportation to the laboratory and during the specimen preparation for cyclic triaxial testing. Thawing takes place only once the confining pressure is applied. This work has also been extended to gravels by Hatanaka et al [29]. An alternative, suggested by Hughes [32] for obtaining data on the cyclic degradation of saturated sands, is to perform cyclic in situ testing with a selfboring pressuremeter.

\section{DESIGN LOADING}

Earthquake design loadings are derived from horizontal accelerations which produce inertia forces at the centre of mass of the building, which in turn generate a base shear and 
overturning moment at the foundation level. Earthquake recordings typically have three orthogonal components: one vertical and two horizontal. Recorded vertical accelerations are usually significantly less than the horizontal, consequently vertical accelerations are not commonly considered in aseismic foundation design (although one needs to be aware that the bearing capacity of a foundation subject to moment is very sensitive to vertical load). Since the maxima in the two horizontal directions do not occur simultaneously many loading codes give methods for combination. The Uniform Building Code [35], for example, specifies that loadings are to be derived from $100 \%$ of the prescribed seismic actions in one direction plus $30 \%$ acting in the perpendicular direction. Alternatively the square root of the sum of the squares in two orthogonal directions can be used. The NZ Loadings Standard [94] is the exception in this matter, as design actions are derived from unidirectional earthquake motion.

The simplest level for assessment of the design loading is a building code which gives a mandatory level of earthquake excitation for routine design. A response spectrum is the usual way of portraying the frequency content of a given earthquake motion. We need to distinguish between the spectrum for a recorded ground motion and that used for design. The former will contain peculiarities of the particular motion. A design spectrum, on the other hand, presents a smoothed curve which attempts to represent the main features of the motions expected to occur at a given site. For important or unusual structures a site specific study is commonly used to develop a design spectrum that takes account of the seismicity of the region, the details of the soil profile at the site, the importance of the facility, and the consequences of failure. There are good discussions of the procedures for developing design spectra in Gupta [28] and Clough and Penzien [17]. A refinement in the preparation of design spectra is the processing of recorded ground motion data to yield curves having, at each period, the same probability that the spectral acceleration will be exceeded. Such uniform hazard spectra are not achieved by simply averaging a large number of recorded ground motions. Simplified methods for deriving these are explained by Clough and Penzien [17] and by Loh et al [51].

Code provisions generally have two levels for earthquake resistant design of buildings. In New Zealand these levels are expressed in terms of limit state design [94]. Loadings at the serviceability limit state (SLS) may occur a few times during the life of the structure. The structure and foundation system are proportioned to resist the intensity of ground motions associated with this event without significant damage. Secondly, there is the ultimate limit state (ULS) event which is envisaged as causing significant structural damage without endangering life by the collapse of the building. Foundation performance criteria are different for the SLS and ULS events. For the SLS loading there will be mobilisation of a larger proportion of the foundation capacity than occurs under gravity loading but a reasonable margin against foundation failure is still required. In the ULS case the norm is the mobilisation of a large proportion of the foundation capacity with consequent permanent deformation.

For the ULS an inelastic design spectrum, specified in terms of structural ductility, is the basis for deriving the design actions. In NZ capacity design principles are followed. In effect we then have two sets of loads to consider for the ULS case - those from the code requirements and those from capacity design considerations. In capacity design a ductile yield mechanism is adopted and the structure and foundation are proportioned to ensure that the chosen mechanism is the only one possible. This requires the remainder of the structure, including the foundations, to have a nominal strength in excess of the maximum possible strength of the yield zones in the mechanism. These strengths are controlled by member overstrength and consequently the resulting foundation actions are usually larger than the code ULS actions. Thus for the capacity actions the mobilisation of even more of the foundation capacity is accepted than in the ULS case. Some capacity design mechanisms involving foundation failure suggest themselves but, as structural capacities can be more reliably specified than those of the foundation, more confidence can be placed on mechanisms which restrict ductile behaviour to the superstructure. Structural engineering viewpoints of the foundation requirements for capacity design are given by Taylor and Williams [101] and Paulay and Priestley [72].

Internationally there have been several large earthquakes causing much damage to buildings and infrastructure in the last decade or so. The large expenditure required for re-establishment means that there is currently a trend towards strengthening the ultimate limit state requirements to protect investment as well as life.

The factors which affect the earthquake motion at a given site are: earthquake magnitude, distance from the causative fault, the nature of the motion at the earthquake source, the wave path between source and site, the site topography (surface and subsurface soil-rock boundary), the soil type(s) present, and details of the soil profile. The last three of these refer to site effects which are the particular local features influencing the earthquake motion that will be recorded at the ground surface. For a level ground site, in which the lateral extent of the soil profile is considerably wider than the depth of the soil layer, useful insight into site effects is obtained by assuming that the earthquake motion is generated by one dimensional vertical propagation of shear waves. If one considers the soil to behave in an elastic manner then seismic excitation at the surface of the soil will be amplified with respect to the motion at an adjacent rock outcrop. The amount of amplification depends on the damping in the soil and the contrast in properties between the soil and the underlying rock, but not on the depth of the soil layer (although this affects the period of the soil layer) Geotechnical engineers have long held that soil is a nonlinear material with the consequence that, as the level of earthquake excitation increases, the amplification caused by the soil will be reduced. There has been a spirited discussion of this between the geotechnical community and seismologists and geophysicists. A gradual resolution of this debate, reviewed by Pender [76], has occurred since the Mexico City earthquake of 1985 with additional new information presented by Iwasaki [38] and Beresnev et al [4]. Although the evidence for nonlinear behaviour is now quite strong, recent earthquakes have lead to further developments in the understanding of the site effect phenomenon by geotechnical engineers. It has been recognised that clays with a high plasticity index behave in a more or less elastic manner at shear strains much higher than $10^{-4} \%$. The main evidence for this was obtained from the Mexico City earthquake of 1985 with further indications from recordings on San Francisco Bay Mud obtained during the 1989 Loma Prieta earthquake. An additional consequence involves the relative values of the recorded ground accelerations at the surface of a soil profile with respect to those at an adjacent rock outcrop. At some ground motion intensity, the rock outcrop and soil surface 
PGA will be the same. For rock outcrop PGA values less than this the soil surface values are larger, for values greater the soil site values are attenuated. It used to be thought that this "crossover" acceleration was of the order of $0.1 \mathrm{~g}$. It now appears that the cross-over does not occur until the rock PGA is as large as $0.3 \mathrm{~g}$ or more, Idriss [34]. More data, for which we are totally dependent on the recording of earthquake ground motions on suitable soil profiles, is required to confirm this.

Guidance given in design codes on handling site effects lags behind this maturing understanding. There has recently been a concentrated effort to revise the soil profile factors for the United States Uniform Building Code. A preliminary report on this work is given by Martin and Dobry [55]. Other information is given by Borcherdt [5] and Seed et al [89].

\section{SOIL PROPERTIES}

Aseismic foundation design requires information about cyclic soil strength and stiffness. As the number of cycles during an earthquake is not large, the information required is rather different from that needed for a foundation subject to a large number of cycles, such as a machine foundation or the subgrade for a highway. For cohesive soils, the liquidity index is a good indicator of likely behaviour under cyclic loading, whereas for cohesionless soils the relative density is the comparable parameter.

For both cohesive and cohesionless soils the shear wave velocity profile gives an upper bound on site stiffness and natural frequency. This velocity is obtained indirectly from penetrometer correlations or directly from in situ measurements. The traditional in situ technique is cross hole determination, but more recently the seismic CPT, which gives an average velocity between the surface and the depth of the cone, has become popular. In addition the geotechnical characterisation of sites using the spectral analysis of surface waves, Stokoe et al [95], has recently become feasible for routine work because of the relative ease with which data from recorded motions can be processed to obtain a shear wave velocity profile.

\section{Undrained Properties of Clay}

The dynamic undrained shear strength of saturated clay is expected to be greater than the static value because of rate of loading effects, Chaney and Pamucku [14]. The very extensive testing of Andersen et al [2] reveals that the post-cyclic undrained shear strength of insensitive clays, even after large numbers of cycles, is not' much different from the static value. This suggests that the post-earthquake capacity of a foundation will not be greatly affected by the cyclic loading. For sensitive clays this conclusion has to be modified as mobilisation of the peak strength will lead to cyclic degradation, Zeevaert [120].

Another aspect of the undrained strength is the effect of the mode of shearing. Andersen et al [2] show that the undrained strength in triaxial compression is greater than that in simple shear which in turn is greater than that in extension. Ohta and Nishihara [68] have shown how this relation can be expressed in terms of fundamental soil properties. Although this understanding has been obtained from static test results it is expected to be as, or even more, important for cyclic testing.
The small strain shear modulus of clay, $G_{0}$, is a function of the void ratio and the square root of the effective consolidation pressure as well as the time the material has been at the current state of consolidation. As mentioned above, when discussing site investigation, the preferred method for determining $G_{0}$ is in situ measurement of the shear wave velocity. If this is not available then correlations with the penetration resistance, Kulhawy and Mayne [45], are available. Laboratory testing on "undisturbed" specimens usually gives values different from in situ measurements, Kokusho [44]; this is attributed to sample disturbance and not testing the laboratory specimen at the in situ effective stress.

The undrained stiffness of clay in cyclic loading is well known to depend on the shear strain amplitude. The apparent shear modulus decreases and the equivalent viscous damping ratio increases with cyclic strain amplitude. The shape of the $\mathrm{G}-\gamma$ curves is also a function of the plasticity index of the clay. For low plasticity clays the behaviour is approximately elastic for shear strains less than about $10^{-4} \%$. High plasticity index cohesive soils behave in an elastic manner for shear strains considerably larger than $10^{-4} \%$. This became apparent after the Mexico City earthquake of 1985 . Available laboratory test data have been summarised by Sun et al [97]. It is of note that, for the range of frequencies of interest in earthquake loading, the mechanism of the damping is hysteretic and independent of frequency, Taylor [98].

The degradation in stiffness of clay is associated with the development of excess pore pressure. Data about the effect of cyclic shear strains on the undrained stiffness and pore pressure build-up is given by Chaney and Pamukcu [14] and by Yasuhara [116]. It has been found that for normally consolidated clays shear strains less than about $0.05 \%$ give no pore pressure rise and that this threshold strain increases with overconsolidation ratio, Matsuda and Ohara [56]. (Note that this result is consistent with the earlier comment about the liquidity index as an indicator of cyclic soil behaviour.) This is an important aspect of the cyclic behaviour of clay as it suggests that for small strains a total stress analysis gives adequate modelling of the seismic response.

\section{Undrained Properties of Saturated Sand}

The first thing to say about the undrained cyclic behaviour of saturated sand is that it is a very complex phenomenon for both the loose and dense states. A good presentation of this complexity is given by Ishihara [37]. It appears that there exists a characteristic stress ratio $\left(\tau / \sigma^{\prime}\right)$ in both compression and extension which divides an inner zone of relatively stable behaviour from an outer zone in which there is a marked degradation in the undrained behaviour of the sand. When the stress path crosses this line large cyclic shear strains are generated. Ishihara, Tatsuoka and Yasuda [36] call this the phase transformation line. Vaid and Chern [108] and Negussey et al [63] found that the angle of phase transformation is virtually identical to the constant volume friction angle for the sand. The laboratory test data for other than very loose sand show that, provided the cyclic shear stresses are within the phase transformation lines, the cyclic shear strains continue to be small, despite the increase in pore water pressure.

Similar to low plasticity clay, the small strain stiffness of sand is approximately elastic at shear strains less than $10^{-4} \%$ and a function of the void ratio and the square root of the effective 
consolidation pressure. Kokusho [44] demonstrates that comparisons between laboratory and in situ values of the shear wave velocity of sand are no better than those for clay. The apparent shear modulus, like that for clay, decreases and equivalent viscous damping ratio increases with cyclic shear strain amplitude. Also there is a threshold shear strain, about 0.005 to $0.01 \%$, for the build up in pore water pressure during cyclic loading, Ladd et al [46].

Finally, the undrained shear strength of a saturated sand is needed for making estimates of foundation capacity. However there is no clear definition of the undrained strength during cyclic loading because of the complexity of the cyclic stress strain behaviour mentioned above. It is clear, though, that regardless of the definition, the undrained shear strength depends on the effective stress in the sand prior to cyclic loading. Recent laboratory data has shown that the undrained shear strength depends on the mode of deformation and that the strength in extension is significantly less than that in compression. Vaid and Thomas [107] and Negussy and Islam [62] have demonstrated this for static loading, but similar behaviour is expected of cyclic test results. This is not unlike, but more severe than, the behaviour noted above for clay.

Liquefaction is likely to occur in young, loose, saturated sand having a particle size distribution in the critical range [102] New construction of shallow foundations in such soils is unlikely, but liquefaction may occur adjacent to pile shafts, indeed liquefaction potential may be the reason for the selection of a pile foundation. In this case, information is necessary about the lateral support available (small) or the drag that will be exerted on the pile as liquefied soil moves past during lateral spreading. In some cases the undrained strength of the sand after liquefaction will also be required.

\section{DESIGN ANALYSIS}

Design analysis, in the description given above of the geotechnical design process, involves the calculations and numerical analyses that are done to provide understanding of the likely behaviour of the proposed foundation system. Usually the quantities that are to be estimated are the capacity of the foundation system and the displacements induced by the applied loads, both short term dynamic loads and long term static loads. These calculations are, of course, only as good as the quality of the data we have about the soil properties. Thus there is strong link between design analysis and the process of obtaining of soil data.

Sometimes solutions are reached not by use of analysis but by brilliant insight; a good example is the solving of the potential static liquefaction problems with the Cape Kennedy Causeway discussed by Peck [73]. In other cases, the application of hard earned experience along with good construction practice is the mainstay of "design". Generally, however, some type of analysis and calculation sequence forms part of the geotechnical design process. The challenge of these calculations is to handle the complexity that is the norm rather than the exception in geotechnical engineering. The problems are inevitably difficult because we deal with a material the strength and stiffness of which may change during the life of the facility, which has properties difficult to determine because of sampling, size, and apparatus effects, and because soil exhibits non-classical behaviour such as nonlinearity and dilatancy. In addition to difficulties with material properties, we have complications as the soil has been formed by natural processes rather than placed in compliance with a specification. This will inevitably give properties which vary from point to point across a site, and there may also be layering or even more complex configurations of different materials. Coupled with this there are the boundary conditions which must be satisfied for the application of numerical methods.

To make progress with this analysis it is necessary to adopt a model, or a series of models, to represent the foundation under investigation. The essence of this modelling is the idealisation of the situation at hand to reduce the real complexity to an acceptable level. It is generally helpful to envisage this as taking several stages, starting from very simple models, which have easily evaluated mathematical forms, and progressively engaging more sophisticated approaches, requiring the application of numerical methods, until sufficient understanding of the problem at hand is reached to enable a design to be finalised. In this way, the insights gained from simple models serve as stepping stones to the final solution and as points of reference in evaluating the results of sophisticated calculations. Linear elasticity and the Mohr-Coulomb strength model are examples of simple models. These are easily criticised but form a good starting place and many solutions associated with these models are expressed in closed form or in forms that are easily evaluated in specific cases. At the other end of the spectrum, realistic models for soil stress-strain behaviour based on incremental work hardening/softening plasticity, or other constitutive relations, do not lead to solutions that can be expressed in simple forms so numerical analysis is required. For a given application, knowledge of the solution to the related linear elastic problem and the related collapse situation gives bounds against which the output from sophisticated numerical modelling can be assessed.

There are two elements of sophistication or complexity in the modelling process. Firstly, there is the basic mathematical complexity of the model itself. And secondly, there is complexity associated with determining the input parameters for the model. Since modern computing facilities are so powerful, a simple model which requires values for parameters which are very difficult to determine, or whose physical significance is not clear, is probably less useful than a complex model which requires values for parameters which are readily determined. Similarly, a model having a small number of parameters is more likely to be useful than one requiring a large number of parameter values. Yet another view of this relates to seemingly small steps up the scale of sophistication. Isotropic linear elasticity is the simplest stress-strain model available and requires just two parameter values to describe a given soil. For a soil deposit formed by sedimentation an anisotropic elastic model, requiring five parameter values, is an obvious step along the path to more realistic modelling. However there is a very substantial jump in the difficulty of determining values for some of these five parameters; in this sense anisotropic elasticity is not a simple model

In view of the challenges of foundation design it is helpful to identify three levels of design analysis. These are:

Level 1: With respect to displacement estimates the soil is assumed to remain elastic during seismic loading. Capacity calculations are done using traditional methods. 
Level 2: At this level "engineering" methods which account for the real behaviour of cyclically loaded soil are used. Approximate techniques are needed to take account of the cyclic loading on the soil strength and the expected cyclic shear strain on the soil stiffness. This is challenging, particularly for foundations embedded in saturated sand. Insight for these methods will come from level 1 approaches, laboratory and field studies, back analysis of the observed earthquake response of foundations, and the methods of level 3 .

Level 3: In this case, a full analysis is undertaken that accounts properly for the dynamic loading, nonlinear soil properties, generation of excess pore pressures during cyclic loading, strain softening, and the complexities of the soil-structure interaction. This is hardly a design analysis, not least because it is usually very difficult to match the sophistication of the numerical modelling with a comparable level of effort in determining soil parameter values. Nevertheless, it is useful for verifying the methods of level 2 .

In solving geotechnical problems it is probably the level 2 analysis that is potentially the most useful design tool. However, it seems at the time of writing (1995) that this level is in need of substantial further development. On the other hand, methods corresponding to level 1 are in a surprisingly good state both for pile and shallow foundations, particularly as many useful results for foundation stiffness have been expressed in the form of simple formulae that can be evaluated with a spreadsheet or similar type of general purpose computational software.

It is necessary to relate the above three levels of design analysis to the two levels of seismic loading discussed earlier. Serviceability limit state design requires that there is no structural damage. The foundation equivalent would be no, or at most small, permanent displacement. However, this does not mean completely elastic behaviour of the foundation soil as such behaviour is limited to a very small strain range. Thus geotechnical design needs to use level 2 methods to arrive at the appropriate soil modulus. Ultimate limit state design of structures founded on shallow foundations allows mobilisation of a considerable part of the foundation capacity but usually not failure.

\section{SOIL - STRUCTURE INTERACTION}

A basic step in the design analysis process for foundations subject to earthquake motion is to consider the effect of the soil compliance on the response of the structure. This comes under the heading of soil-structure interaction and requires the development of a model to represent the structure-foundation system.

Estimation of the displacement during earthquake excitation can be done relatively easily using an equivalent single degree of freedom (SDOF) model of the structure-foundation system. The formulation of the equivalent single degree of freedom model is explained by Veletsos [109], Wolf [112], and Clough and Penzien [17]. Information on the equivalent stiffness and damping values for soil structure interaction is given by Gazetas [24] and Wolf [113]. The main assumption of this method is that only the first mode of the structure contributes to the response. In essence, the response spectrum approach is iterative as the natural period of the system has to be available before the spectral acceleration, and hence the design loads, can be estimated; but the natural period cannot be determined until the foundation size is available. Thus one starts with an initial guess at foundation size and proceeds in an iterative manner.

An interesting feature of the SDOF model is that the earthquake response at the interface between the structure and foundation is less than that of the of the adjacent free field, Jennings and Bielak [40] and Wolf [112]. The recorded response of buildings on raft foundations, McVerry [59] and Zhao and McVerry [121], confirms that this applies over a considerable part of the frequency range of interest. A similar conclusion can be inferred from recorded data provided by Japanese researchers for structures with pile foundations, Pender [77].

The SDOF model is based on the behaviour of an elastic system. With increasing peak ground acceleration it is expected that the interaction between the structure and the surrounding soil may depart from that given by elastic soil behaviour. As discussed further below, the choice of an appropriate value for the soil modulus is an important aspect of design analysis.

More sophisticated methods of calculation such as modal analysis, time history methods, and dynamic finite element calculations are possible. Even so, the SDOF model coupled with the response spectrum is a good place to start. As explained earlier, one can thus think of a hierarchy of computational methods in which a start is made at the lowest level followed by a progression of ascending complexity until the designer has obtained the required understanding of the foundation performance.

\section{OBSERVATIONAL METHOD}

The observational method is well established in geotechnical engineering as an economical means of dealing with uncertain geotechnical conditions during construction. It has been explained clearly by Peck [73] and reviewed again in a series of papers appearing in the issue of Geotechnique for December 1994. In earthquake engineering, the observational method cannot be used in the sense defined by Peck as earthquake loading usually occurs well after construction is complete. However, a type of observational method provides very important input to the process of aseismic foundation design. This is the gradual piecing together of our understanding of foundation behaviour derived from observation of performance during earthquakes and/or the instrumental monitoring of the response of foundations. The monitoring of foundation accelerations and the recording of pore water pressures in the soil beneath yields valuable information. The Japanese earthquake and geotechnical community has been exceptionally active in producing such data. Many other countries which experience earthquakes also undertake this type of monitoring. The installation and maintenance of such instrumentation is expensive but the information resulting is of inestimable value to the earthquake engineering community.

\section{DESIGN DECISIONS}

Before discussing design analysis for the various foundation types it will be helpful to review some of the understanding that has been gleaned from the application of the observational method discussed above. 
The basic criteria for satisfactory foundation performance will be in terms of allowable deformations and the required capacity. In this sense, design for seismic loading is no different from that for static loading, the only difference being mobilisation of a greater proportion of the foundation capacity with the likely consequence of some nonlinear soil deformation. A prerequisite for achieving this is that the foundation has adequate static capacity and stiffness. Many of the foundation failures in the 1985 Mexico City earthquake were attributed to pre-earthquake loads mobilising too much of the foundation capacity, Girault [27], Mendoza and Auvinet [60], and Zeevaert [121].

When the structure is founded in clay, it is clear that undrained properties of the clay will determine the earthquake response of the foundation. For a foundation in sand this is not quite so clear. Investigations of pore pressure dissipation beneath impermeable rigid rectangular foundations on the surface of a deep layer of homogeneous soil, Davis and Poulos [19], reveal that the consolidation time is related to the square of the foundation dimension. It turns out that, for the range of permeability associated with sand and foundation dimensions of a few metres or more, the consolidation time is a significant fraction of the duration of a typical earthquake. During cyclic loading there is a progressive build up in pore water pressure so one concludes that undrained, rather than drained, strength and stiffness will control the earthquake response of all but small footings in saturated sand.

An important question for foundations in saturated sand is liquefaction. The criteria for this are sufficiently well understood that new construction of shallow foundations would not occur at sites with loose sand until appropriate ground improvement has been done. Thus the design of shallow foundations on saturated sand is limited to the dense sand case. On the other hand, difficult questions regarding the effect of liquefaction arise in the assessment of existing foundations on loose sands.

In the remainder of this section suggestions for what is regarded as good practice for aseismic foundation design are listed These could be considered an extension of the suggestions given by Arnold and Reitherman [3] on structural forms which give good performance under earthquake excitation. As such these are not "rules" but suggestions for good practice. If it is necessary to do otherwise, then prudence demands special consideration during design. The recommendations are as follows:

(i) Foundations in soft soils have been observed to be more severely damaged during earthquakes than those in firm ground. (In this context the description "soft" refers to soils which will not be subject to liquefaction). The effect is accentuated when there is an abrupt contrast in properties between the soil layer and the underlying rock. Recent evidence comes from the 1985 Mexico City event, Kalamata (Greece) 1986 [25], Armenia in 1988, Loma Prieta in 1989, and Newcastle in 1989 [82]. Earlier evidence is summarised by Ohsaki [67], and Seed [88]. A reasonably complete record of Japanese experience is given by Kanai [42]. In the earlier comments on design loading it was explained that the provisions of many code documents need refining to more adequately represent this effect. Further to these observations, structural damage has been found to be more severe when the natural period of the soil profile and the first mode of the structure are similar, Seed [88]. (ii) As a general principle, one should aim to have foundation elements with similar stiffness. Thus, for example, a foundation system which has shallow footings on one side of the building and piles on the other needs careful consideration so seismic load paths are understood. A particular example of this problem relates to pile foundations when some of the piles are raked. It is well known from post-earthquake observations that raked piles are often severely damaged. This is readily understood if one compares the head stiffness of a raked pile with that of a vertical pile. It is found that the stiffness of the raked pile is much greater than that of an equivalent vertical pile [77]. Satisfactory performance is possible if this fact is accounted for at the design stage.

(iii) For light framed structures foundation elements should be tied together. This is an insurance against individual foundation elements not performing satisfactorily Eurocode 8 [13] gives recommendations for the required tie capacity.

(iv) Related to the above comment about foundation elements having similar stiffness is the recommendation, derived from observation of foundation performance during earthquakes, that special consideration be given to the possibility of differential movement if adjacent parts of a structure are on different foundations. This is particularly likely with the combination of shallow foundations on sand and end bearing piles. The shallow foundations settle during and after the earthquake whilst the piles do not. A further aspect of this is the effect on service connections to the structure. An example of this is given in Fig. 2.8 of [77]. Even if the building foundation consists only of end bearing piles there remains the possibility that the service connections will be ruptured if the soil adjacent settles and the connections have not been specially designed to accommodate the relative movement

(v) When shallow foundations are constructed near to the causative fault the question of ground rupture beneath or adjacent to the foundation must be considered. Dobry [20] has reviewed earthquake damage data and confirmed that permanent ground deformation has a more disruptive effect on shallow foundations than the shaking during the earthquake. Youd [119] gives criteria for tolerance of various types of structure to different modes of deformation.

(vi) When deciding on a pile foundation system for a structure, one needs to check that a pile solution is really the most appropriate. Particularly in irregular soils, or where downdrag is likely to occur, the designer may sometimes have more confidence in the performance of shallow foundations. An additional problem with downdrag is that it may mobilise a large amount of the downward capacity of the pile shaft, so that when the earthquake occurs the required pile shaft reserve capacity is not available. This seems to have been at least part of the problem for some of the failed foundations in Mexico City in 1985, Girault [27].

(vii) The design of structures founded on end bearing piles through sand should never assume that any capacity can be derived from bearing in the underside of the foundation raft or slab. The reason is that the sand may settle away 
from the underside of the foundation requiring all the load to be carried by the piles.

(viii) In designing pile foundations one needs to be aware that when the soil profile has adjacent layers with very different properties these boundaries may be the focus of severe damage. Japanese investigations have shown that this damage can occur at considerable depth [77].

(ix) Pile foundations are often used when the upper layers of the soil profile are liquefiable. When liquefaction occurs the pile shafts will be subject to large moments and much reduced lateral stiffness as liquefied sand will exert little restraint. This in effect introduces a "soft storey" into the system. However, there are cases in which pile foundations have undergone yielding and lateral displacements and yet the building has performed satisfactorily for a long period after the earthquake, section 2.1 of [77].

(x) When piles are driven through a soft soil to end bearing on a deep sand stratum one needs to consider the possibility of liquefaction of this deep layer and the consequent loss of end bearing. The sand layers could be deep enough that there would be no surface manifestation of the liquefaction

(xi) Regarding pile foundations (particularly end bearing piles) in liquefiable sands, one is sometimes asked about downdrag effects as the sand settles during the liquefaction. This is unlikely to be a source of difficulty as there will be no downdrag force because the effective stress between the pile shaft and liquefied sand will be zero.

(xii) Lateral loading of piles in clay leads to the formation of a gap between the pile shaft and surrounding soil near the ground surface. This is illustrated in Fig. 2.8 of [77]. Clearly this affects the pile lateral stiffness and vertical load carrying capacity.

(xiii) When pile groups are loaded laterally, the piles of the leading row carry more of the load than the trailing piles. This is known as shadowing and has been measured in groups in clay and sand for monotonic loading as well as cyclic loading (but not, to the knowledge of the author, during earthquake loading), Brown et al $[9,10]$. The extent of the shadowing depends on the lateral deformation. Tests on the lateral loading of a $3 \times 3$ pile group, Ogasawara 'et al [66], indicate that for lateral deformations up to about $4 \%$ of the pile diameter the distribution of load is similar to that calculated if the soil is assumed to behave elastically. For larger displacements the trailing piles carry progressively less of the applied load.

(xiv) Care is needed in assessing the cyclic axial shaft capacity as a mechanism for resisting the cyclic moment generated during the earthquake. This is because the capacity degrades, in some cases quite severely, once the full capacity is mobilised.

(xv) Subtly different from (xiv) is the observation of Zeevaert [121] about the sudden settlement of some buildings on partially compensated pile-raft foundations during the Mexico City earthquake of 1985 . He suggests that the pile group capacity was such that the static building loads were carried by the piles alone and a gap had developed between the underside of the foundation and the soil. During the earthquake the full capacity of the piles was mobilised and the whole structure plunged downward until the gap was closed. Zeevaert recommends that pile-raft foundations should be proportioned so that the full pile group capacity is less than the static loads, thus requiring some bearing on the underside of the foundation and so preventing the formation of any gap. This means that the full downward shaft capacity may already be mobilised when the earthquake occurs, in which case the couple resisting the applied moment is generated from the upward capacity of the piles on one side of the building and additional bearing pressure beneath the other side.

\section{DESIGN ANALYSIS FOR SHALLOW FOUNDATIONS}

The subdivision of this and the following section into capacity calculations and displacement estimates is done for convenience, as the design process often requires iteration between capacity and displacement considerations, even though, in some situations, the distinction becomes blurred. We also need to consider which is the critical direction for earthquake attack. For square foundations this is generally across a diagonal as this has the smallest effective foundation bearing area.

In what follows, those topics that are in need of development are marked at the end of the relevant sentence(s) with the symbol: (2).

It is necessary to consider design analysis for shallow foundations in saturated sand and clay separately because the undrained cyclic properties of sand are so much more complex than those for clay.

\section{Shallow Foundations in Clay}

Capacity - level 1. The capacity is estimated using conventional bearing capacity theory modified to include seismic inertia effects on the soil beneath the foundation.

In principle mobilisation of a significant proportion of the undrained capacity is permissible, both for the serviceability and ultimate limit states, because of the transient nature of the seismic loads.

For the SLS earthquake there are four reasons for wishing to limit this mobilisation and the consequent permanent deformations. Firstly, service connections to the structure, e.g. power, telecommunication, sewer and water supply lines, may be ruptured by rotations large enough to become permanent. Secondly, for tall structures, residual rotation of the foundation is undesirable for aesthetic reasons. Thirdly, it is necessary to investigate foundation capacity under seismic loading carefully as the combination of moment and shear reduces the reserve of strength very rapidly, an effect which is not indicated in the conventional static factor of safety. The final factor is the usual decision not to include the vertical earthquake acceleration in the capacity assessment, even though bearing capacity is critically dependent on the vertical load, and so it is not prudent to go too close to mobilisation of full capacity. The justification for not considering the vertical acceleration in the design analysis is the assumption that the worst horizontal and vertical earthquake excitations will not occur at the same instant. 
For the ULS it is uncommon, as explained above in the Design Loading section, to allow the full capacity of the foundation system to be developed although a larger proportion will be mobilised than for the SLS event.

Additionally it is necessary to investigate the effect of the seismic acceleration in the soil beneath the foundation. This has been investigated only recently and most of the papers do not distinguish specifically between drained and undrained effects, Sarma and Iossifelis [86], Shi and Richards [90] et al, consequently the required information is not given. Furthermore, these analyses lump both inertia and inclined load effects into one factor. Since there are well established empirical factors to account for inclined load effects on shallow foundation capacity we need to be able to separate the interplay of inclination and inertia to gain a proper appreciation of the effect of the latter. When undrained behaviour is investigated it is found, as expected, that the inertia effect in the soil beneath the foundation reduces the capacity. Interestingly the reduction depends on the width of the foundation, the dimensionless quantity that specifies the effect is $\gamma \mathrm{B} / \mathrm{s}_{\mathrm{u}}(\gamma$ - the unit weight of the clay, $s_{11}$ - the undrained shear strength, and B - the width of the foundation). This is illustrated by Pecker and Salencon [74] and Ghahramani and Berrill [26]. The conclusion is that for typical footings the seismic inertia effect is not significant, but for large raft foundations it is important. Pecker and Salencon also emphasise that the effect becomes increasingly important as the static factor of safety is reduced (2)).

Capacity - level 2. There are no readily identifiable methods in this category of design analysis.

Capacity - level 3. In this case we are more concerned with a nonlinear deformation analysis in which capacity and deformation considerations merge.

Deformation - level 1. At this level, elastic behaviour of the soil is appropriate. Although this is not the strain level one would anticipate in the soil beneath a foundation for even the SLS loading, it does yield an upper bound on the natural frequency of the SDOF model of the structure foundation system. One can then be confident that the response of the system under the SLS and ULS events will occur at smaller frequencies.

A quite remarkable achievement in geotechnical engineering in the last couple of decades has been the development of a comprehensive range of solutions for elastic foundation stiffness (both static and dynamic) and damping values, Gazetas [24] and Wolf [113]. Furthermore these solutions are expressed as simple formulae which can be evaluated using a spreadsheet or similar general purpose computational environment. This is particularly convenient when exploring alternative designs as it is not necessary to go through the laborious process of referring to design charts. One can ask about the limits of the range of these elastic solutions. The first answer is to say that they are valid for the small strain range of soil behaviour; but this can be extended to the range for which there is no generation of pore pressure, although we would then need to use a soil modulus less than the small strain value.

Deformation - level 2. For this level of analysis we have three points to consider:

(i) We need the natural frequency of the SDOF model at the shear strains in the soil beneath the foundation during SLS earthquake. Judgement is needed about how much the apparent shear modulus of the soil is less than the small strain modulus. The simplest approach is that given in Eurocode 8 [13] where a reduced modulus related to the earthquake peak ground acceleration is suggested (2)). This modulus is then used in a pseudo-elastic manner to give the natural period of the system and from there to the earthquake loads via the design response spectrum. Alternatively, methods using a Winkler spring formulation for nonlinear soil-structure interaction beneath rigid foundations have been developed by Taylor et al [100] and a slightly different approach, with a hyperbolic foundation moment-rotation relationship, has been proposed by Pender [75].

At this level there is also need for some way of incorporating the sensitivity of the clay and the possibility for degradation of the soil modulus during the cycling. The liquidity index of the clay is a good indicator of whether of not this effect will be significant; high values of the LI suggest the possibility for cyclic degradation (2))

(ii) For the ULS earthquake the loads are limited by the ductile capacity of the structure. A common question is the effect of soil-structure interaction on the ductility demand. Ciampoli and Pinto [15] report on a parametric study which concludes that the inclusion of the foundation compliance nearly alway's reduces ductility demand.

(iii) Also we need to consider settlement of the foundation subsequent to the shaking. This will occur if any excess pore water pressure was generated during the earthquake. This settlement estimate is simple if we know the pore water pressures generated. The work reported by Matsuda and Ohara [56] gives insight on whether the shear strains are large enough to initiate build-up in pore water pressure. Hyodo et al [33] suggest a method for making the settlement estimate.

Deformation - level 3. At this level, the primary purpose of which is to validate the level 2 techniques rather than act as a design method as such, one makes use of sophisticated numerical methods to produce nonlinear dynamic solutions to foundation response under earthquake. The simplest of these would be application of the equivalent linear method to model soil behaviour (this is a two dimensional equivalent of the well known SHAKE programme for one dimensional site response) Hudson et al. [31]. Use of such a programme could, for example, be used to verify the recommendations of Eurocode 8 [13] on the reduction of the soil modulus as the PGA rises. At a more advanced level a proper nonlinear incremental formulation of the soil behaviour, such as that used by Borja et al $[6,7]$, gives information about permanent deformations.

\section{Shallow Foundạtions in Sand}

behaviour of saturated sand is, as explained above, very complex. Recall though that we are dealing with dense sand only and so the severe degradation in stiffness and possible liquefaction which occurs on the cyclic loading of loose saturated sand does not have to be considered. Nevertheless, this situation also requires a workable design analysis method which does not seem to be at hand. In fact current practice is not much beyond the observation that shallow foundations on dense saturated sand perform satisfactorily in moderate earthquakes 
Capacity - level 1. In this case we need to consider the undrained capacity of the foundation. This is more complex than the clay case. First we need to recognise that the undrained strength of the sand is a function of the effective stress in the sand prior to the earthquake. This means that the sand beneath the foundation will have more undrained strength than the sand to the sides. Secondly, the sand beneath the foundation will be deformed in a compressive mode and whilst that to the side is in extension. As explained above the undrained strength of sand in extension is less than that in compression. This, then, gives two reasons why the sand to the side of the foundation cannot be expected to contribute much to the foundation capacity. As we are talking about undrained capacity the width effect mentioned for shallow foundations on clay also applies to shallow foundations in sand. The analysis of the undrained capacity for this situation requires development (2)).

Capacity - level 2. At this level we need to be able to assess the effect of cyclic degradation on the undrained strength of the sand which, in turn, affects the capacity. Model tests, reported by Taylor et al [100] on the rocking of a shallow foundation in dry sand show a tendency for the footing to dig itself into the sand, this is likely to be even more significant for a foundation in saturated sand. An important aspect of this is the stress path followed and whether or not the phase transformation line is crossed (2)). This crossing is unlikely to occur if the shear strains are less than the threshold value for pore pressure generation. If the crossing does not occur then the capacity can be reliably assessed using the level 1 approach otherwise we have to consider the level 2 or perhaps the level 3 deformation analysis. Depending on the permeability of the sand and the size of the foundation, dissipation of the pore water pressure during the shaking may be significant (2). This is particularly likely if the sand is layered as discussed for one dimensional behaviour by Marks et al [54].

Capacity - level 3. In this case we are more concerned with a nonlinear deformation analysis so capacity and deformation considerations merge.

Deformation - level 1. As for the clay case, a good range of elastic solutions is available. However a sand deposit will not be homogeneous because the stiffness increases with depth. Recently Pak and Guzina [71] have presented solutions for vertical vibration which allow for this inhomogeneity. These need to be supplemented with those for horizontal and rocking vibration (2)

Deformation - level 2. The same three issues discussed above for foundations in clay arise here. Dynamic tests of shallow foundations on sand with relative density in the 35 to $65 \%$ range, done in a centrifuge by Madabhushi and Schofield [53], Liu and Dobry [49], and Zeng [122], and with a shaking table by Yoshimi and Tokimatsu [118], all show that the peak pore pressure ratio approaches unity to the side but not beneath the foundation. Degradation of stiffness will be critical if the large pore pressures diffuse sideways into the region beneath the foundation during the earthquake. On the other hand Fukutake et al [22] performed shaking table tests of a rigid structure on saturated sand with a relative density of $90 \%$, the maximum pore ratio observed was 0.7 . An important priority here is to understand these processes; how the magnitude and distribution of the excess pore pressure and the cyclic degradation in the stiffness are related to the relative density of the sand. From there a design method needs to be developed (2)).
Yoshimi and Tokimatsu [118] report on shaking table investigations of the effect of ground walls (vertical walls constructed on each side and at the edge of the foundation) intended to restrict the lateral transmission of high pore pressures into the region beneath the shallow foundation. As explained in the previous paragraph delaying this until the earthquake has passed is desirable.

Deformation - level 3. As with the clay case this level blurs the distinction between capacity and deformation estimates. Here we need to be able to calculate the response of a shallow foundation to dynamic loading with nonlinear stiffness and increasing pore water pressure. As yet there are very few examples of this type of analysis for two and three dimensional response (2)). It is well established for one dimensional liquefaction assessment. Recently the provision of input data for these models has been simplified by basing the pore pressure parameters on the standard penetration resistance, Byrne and McIntyre [11]. The results of implementing this model in a one dimensional site response programme are discussed by Larkin and Marks [48]. More sophisticated is the work reported by Fukutake [22] in which a model for the undrained cyclic behaviour of dense sand is given a two dimensional finite element implementation. Comparisons between shaking table and computed response of a rigid block structure on dense sand are presented. This work indicates that for a relative density of $90 \%$ there is degradation in stiffness but no residual settlement or rotation.

\section{DESIGN ANALYSIS FOR DEEP FOUNDATIONS}

The preliminary comments from the above shallow foundation section also apply here. Under this heading we consider isolated piles, free-standing pile groups (no contact between the soil and the underside of the foundation structure), and pile-rafts. We also need to keep in mind that the earthquake loading comes to the pile from below, so the manner in which the pile modifies the incoming motion must be addressed. It is known that the free field motion at the surface of a uniform soil profile is not much different from that at the head of typical flexible pile [77]. However, this kinematic interaction effect may be quite important for piles in layered soils. In addition, there is inertial interaction, by which the pile head is loaded from the response of the building to the excitation. These two aspects of pile-soil interaction play an important role in aseismic pile design; they are discussed further in [77].

\section{Pile Foundations in Clay}

Capacity - level 1. Traditionally pile shaft and base capacities are estimated separately. The base resistance comes from a deep bearing capacity calculation. The shaft capacity can be estimated from a total stress approach, defended by Sladen [92], or an effective stress method, Randolf and Wroth [84]. It is also possible to estimate these values directly from penetrometer resistance or from a wave equation analysis of the pile driving process. The long term loads are dominantly vertical and the vertical capacity of a single pile is readily estimated with these methods. Pile group vertical capacity can be estimated using equation 3.24 of Poulos and Davis [81].

During earthquake loading horizontal shear and moment must also be considered. For single piles, methods for estimating the shear and moment capacity are reviewed in [77]. Modern foundation construction methods favour large piles, for a multi- 
storey building one at each column position, rather than groups of closely spaced piles. Nevertheless, this foundation system is still a pile group and typical spacing to diameter ratios are in the range 5 to 10 . The pile groups must then resist the foundation shear and moments, perhaps in conjunction with bearing on the underside of the raft as explained in item $\mathrm{xv}$ of the Design Decisions section. Some suggestions for estimating this capacity are given by Pender [77] but further development is needed particularly for the pile-raft case where we lack a method of partitioning the seismic capacity between the pile group and the raft and allowing for the effect of pile shafts passing through the bearing capacity mechanism (2)). The contribution to capacity derived from earth pressures on basement walls (discussed further below) also needs to be considered

Capacity - level 2. There are three separate considerations here. A pile group foundation is able to resist the applied moment by generating a couple from asymmetric axial loading of the piles on opposite sides of the foundation. The piles on one side have a downward load increment and those on the other an upward increment. Indications are that the shaft capacity degrades rapidly when subject to cyclic loading. Jaime et al [39] suggest that the onset of degradation occurs when the capacity is initially mobilised. However, McManus and Turner [57] and, for nonseismic cyclic loading, Turner and Kulhawy $[105,106]$ suggest more stringent conditions such as the direction of the average shear stress on the pile shaft should not be reversed. This is an important design issue needing to be resolved (2)). Secondly, a technique for estimating the lateral load distribution in pile groups that accounts for shadowing, explained as item xiii in the above Design Decisions section, is needed (2)). Finally, the phenomenon of gapping, item xii in the Design Decisions list and also discussed under Deformation - level 2 below, will reduce the axial capacity of the pile shaft and so a method of estimating the effect of this on pile axial and lateral capacity is needed (2)

Field performance, item viii in the Design Decisions list, shows that pile shafts can reach capacity at interfaces between soil layers having very different properties, even when these occur at depth. Oweis [70] suggests a simple method for assessing this effect. An investigation focussing on the structural aspects of the required pile shaft capacity at soil layer interfaces is reported by Fussell [23]. Penzien [80] develops a structure-foundation system model with the potential to indicate the presence of severe pile shaft moments. (Were it not for information about pile shaft maximum moments, a more appropriate classification for this method would be Displacement - level 2 or 3, as Penzien uses bilinear Winkler springs for soil-pile interaction.)

Capacity - level 3. In this case we are more concerned with a nonlinear deformation analysis so capacity and deformation considerations merge.

Displacement - level 1. For this case a set of simple elastic solutions for pile dynamic vertical and lateral stiffness is available [77] and Gazetas [24]. A useful concept arising with these solutions is that of active length. For a laterally loaded pile this gives the length of the pile shaft that undergoes significant deformation, if the pile is longer the lateral stiffness is independent of length.

The dynamic stiffness of pile groups is also included in these elastic solutions. It is quite remarkable that a simple formula, based on cylindrical wave propagation, is able to represent well the dynamic interaction between the piles in a group and reproduce the complex frequency dependence of the components of a pile group stiffness matrix. Pender [79] demonstrates that the complex frequency dependence of the components is not carried through to the stiffness of the equivalent SDOF model of the structure-foundation system. For pile-rafts Randolf [85] gives a method for estimation of the vertical stiffness; this needs complementing to cover dynamic shear and moment loading (2)

Displacement - level 2. At this level the Winkler model provides a means of modelling the nonlinear soil-pile interaction for laterally loaded piles. This is well established as a satisfactory method for handling lateral loading of piles in layered soil profiles [77]. One feature of this model is an apparent pile-size dependent stiffness which is contrary to the Terzaghi method for accommodating different sized piles within the Winkler model [77]. Some understanding of this effect has been derived by three dimensional finite element analysis of laterally loaded piles (discussed below).

Pranjoto and Pender [83] report on a preliminary investigation of gapping adjacent to piles in clay. This shows that the gap penetration is of the order of the active length of the pile. As mentioned above, this effect clearly influences the axial capacity of the pile shaft. It also has implications for the lateral stiffness of piles in clay. The lateral stiffness equations, derived on the assumption of elastic soil and pile behaviour, assume that the soil acts all around the periphery of the embedded pile. This assumption is handled with the Winkler analysis by assuming that the soil on both the front and rear of the pile contributes to the stiffness and so the spring stiffness is doubled. However, gap penetration to depths about equal to the active length means that soil on only one side of the pile contributes to the lateral stiffness (2)).

An alternative to the Winkler model for lateral and axial pile loading of single piles and pile groups is proposed by Norris [65]. It is also necessary to have methods for handling the shadowing of laterally loaded pile groups. Duncan et al [21] and Ooi and Duncan [69] propose a method for estimating the average load carried by the piles of a group under static loading, a method of this type is needed for dynamic loading (2)).

Additional useful data from prototype scale testing is presented by Crouse et al [18] who measured the behaviour of a pile in saturated peat subjected to quick release and forced vibration loading. The quick release is less costly than forced vibration but was found to give similar stiffnesses.

Displacement - level 3. There have been a number of fully three dimensional finite element analyses of single laterally loaded piles in cohesive soils, Brown and Shie [8] and Trochanis et al [104]. These provide an explanation of the pile size effect observed using the Winkler model as shear stresses at the soil pile interface incuce an additional moment not considered with the Winkler model. They also confirm the general validity of the simple Winkler model for lateral loading of piles. Analyses of this type also offer potential for understanding better the gapping phenomenon (2)).

Anandarajah et al [1] report on a two-dimensional nonlinear finite element analysis of the earthquake response of a bridge structure founded on pile groups in clay. The calculations were compared with the response of a centrifuge model of the system 
and the matching between the numerical and centrifuge results was found to be reasonable. A comparison of these results with a level 2 SDOF model of the system would be of value from a design analysis perspective.

\section{Pile Foundations in Sand}

The discussion in this section is directed to saturated sand as the design of piles in unsaturated sand does not pose any special problems for either vertical or lateral loading. When dealing with shallow foundations on saturated sand we restricted our considerations to dense sand. For pile foundations this is not so, as the presence of loose sand will often be the motivation for the choice of piles, and we need to consider the undrained interaction between pile shafts and loose sand

Capacity - level 1. Here essentially the same issues arise as for piles and pile groups in clay. One additional concern is the effect of lateral spreading and the pile shaft capacity required to resist the actions generated as liquefied sand flows past. This is a current area of research but a design analysis method is yet to emerge (2)).

Capacity - level 2. Here, also, the same issues arise as for the corresponding case for deep piles in clay. In this case we need to account for the degradation in stiffness which leads to large increases in the bending moments in pile shafts.

Capacity - level 3. In this case we are more concerned with a nonlinear deformation analysis so capacity and deformation considerations merge.

Displacement - level 1. The comments under this heading for piles in clay also apply to this situation.

Displacement - level 2. The critical question here is the stiffness of the loose sand adjacent to the pile shaft and the amount of degradation induced during the earthquake. One-way nonseismic cyclic lateral loading of piles in sand was studied by Long and Vanneste [52] who also reviewed published case histories. They propose a technique, suitable for design analysis, that accounts for the cyclic degradation in stiffness. With appropriate data this could be extended to aseismic design.

McVay et al [58] performed monotonic lateral load tests in a centrifuge on $3 \times 3$ pile groups at 3 and 5 diameter spacing (the piles were driven in flight). The data gained confirms that the shadowing reduces as the pile spacing increases. Their results show that at 3 diameter spacing the load distribution is more uniform for loose sand than for dense. At 5 diameter spacing the three rows carried nearly the same load regardless of the density of the sand. This suggests that shadowing will not be significant in the pile group foundations for multistorey buildings which have typical spacing to diameter ratios in the 5 to 10 range.

Shaking table and centrifuge tests by Nomura et al [64], Yao and Kobayashi [115] and Liu and Dobry [50] of the lateral response of piles in saturated sands show that the degradation in stiffness is very severe. Lam and Cheang [47] review the extremely limited existing data on the cyclic lateral loading of full scale piles in saturated sand, they suggest that the cyclic stiffness is only 10 to $20 \%$ of the static stiffness. More data on this point is required urgently (2)). The centrifuge data of Liu and Dobry [50] also indicate a very substantial reduction in the lateral stiffness
Kagawa [41] has investigated the development of a Winkler pilesoil interaction model which includes the effects of pore pressure increase and stiffness degradation of the sand. Such a method would complement the use of the Winkler model for level 2 analysis of piles in clay.

Nagataki and Senoo [61] considered the use of ground walls for buildings without basements . They investigated the effect of these using shaking table models and three dimensional finite element studies. The ground walls have a similar action to basement walls in equilibrating some of the applied actions through earth pressure (discussed below under basement walls). A simple model is proposed as a design analysis method.

Displacement - level 3. Sophisticated numerical modelling of piles and pile groups in liquefiable sands is an active area of current research, Kobayashi et al [43] and Nomura et al [64]. In the case of the work reported by Shiomi et al [91] a detailed numerical model of the superstructure is also included. It is hoped that eventually the fruits of these and similar investigations will lead to level 2 methods of design analysis.

\section{DESIGN ANALYSIS FOR SEISMIC EARTH PRESSURES ON BASEMENT WALLS}

For this application we need to estimate the increment in earth pressure that is generated by the earthquake. Basement walls are relatively rigid so the seismic earth pressure can be estimated with a displacement $(\approx$ elastic) rather than a capacity design analysis. Two basic questions motivate this interest. Firstly, the need of the structural designer to know what pressures will be acting on the walls. Secondly, it is necessary to understand how these pressures contribute to the equilibration of the earthquake actions.

Displacement - level 1. A well known elastic approach, Wood [114], is based on two dimensional finite element modelling of the interaction between a rigid wall and an elastic backfill. This is presented in terms of simple design charts which enable estimates of the seismic thrust and maximum wall moment. Recently Veletsos and Younan [110] have developed an alternative two dimensional elastic solution which can be evaluated by summation of a series. This gives not only the pressures against a rigid vertical wall but also the variation with horizontal distance from the wall of pressures and displacements in the soil. The limiting case, at large distance from the wall, is the shear stress and displacement distribution in a layer of soil undergoing one dimensional wave propagation. In addition, Veletsos and Younan [111] have extended their solution to handle pressures against circular surfaces. Scott [87] developed an approximate one dimensional model for estimating dynamic earth pressures against stiff walls which is simple to apply and can include the wall modelled as a bed of Winkler springs.

Pender [78] investigated the relative sharing of load between basement walls, the underside of the foundation raft, and piles for various pile-raft configurations; work which was undertaken because of the proposals of Sugimura [96]. As expected, less of the earthquake induced actions are transferred to the piles with increasing numbers basement levels. The stiffness contribution from the base of the raft was found not to be significant for many configurations. 
Displacement - level 2. Huang et al [30] suggests a simple modification of the Scott model involving iteration to obtain the soil modulus appropriate to the shear strains developed. However, considerations at level 3 (below) suggest that the simple elastic method of Scott gives earth pressures not much different from those derived from nonlinear finite element calculations. One concludes that, for this design analysis problem, the methods of level 1 are adequate.

When considering soft clays adjacent to basement walls Taylor and Indrawan [99] point out that the full passive pressure may be developed near the ground surface and propose a method of allowing for this.

Displacement - level 3. Huang et al [30] performed two dimensional dynamic finite element calculations to estimate the earth pressures exerted on a rigid wall by soil having a strain dependent modulus (he used the equivalent linear method with the modulus determined from a G- $\gamma$ curve). The results showed that the nonlinear calculations gave earth pressure increments comparable to those of the simple Scott method. This finding, no doubt a consequence of the small shear strains that are developed in the soil near a rigid wall, is a good example of a level 3 method verifying a much simpler design analysis approach.

\section{CONCLUSIONS}

This keynote lecture has reviewed the geotechnical design process, particularly as it relates to the aseismic design of foundations. To clarify the process the term design analysis was introduced to cover all the calculation and analytical work that is a central part of the design sequence. To further clarify this, three subdivisions of the design analysis process were proposed.

Currently, on the international geotechnical scene, there is underway a large amount of well conceived research work, much of it numerical analysis, that would be classified as level 3. This is the fruit of the spectacular developments in computer facilities that have occurred in the last few decades. There is a limiting factor, though. This is the problem of determination of the required soil data which means that it is very difficult to match the sophistication of available numerical methods with comparable sophistication in the determination of soil properties. However, an important role for level 3 work is the provision of geotechnical insight from which level 2 design analysis methods can be derived.

The paper proposes that level 2 methods of design analysis are most appropriate for practical applications. Here the foundation designer needs to account for expected cyclic degradation effects on the soil strength and stiffness, and also to select modulus values which reflect the shear strain in the soil under cyclic loading. In the opinion of the author the further development level 2 methods should be given high priority in geotechnical research.

Of the level 2 problems the most pressing are associated with saturated sand. In the past three decades there has been a mammoth, and largely successful, effort searching for an understanding of the liquefaction phenomenon and development of methods for its prediction. As yet the understanding of the behaviour of cyclically loaded foundations in saturated sands at or approaching liquefaction is in its infancy.
In the text the many design analysis topics requiring further development are noted; these are highlighted by the use of the symbol (2)

\section{ACKNOWLEDGEMENTS}

The author wishes to acknowledge helpful discussions with colleagues, Dr T J Larkin and Dr R C Fenwick, during the preparation of this paper. Also $\mathrm{Mr} \mathrm{V}$ M Meyer assisted with editing and proof reading.

\section{REFERENCES}

1 Anandarajah, A, Rashidi, H and Arulanandan, K 1995. Elasto-plastic finite element analysis of a soil-structure system under earthquake excitations, Computer and Geotechnique 17(3): 301-325.

2 Andersen, K. H, Pool, J H, Brown, S F and Rosenbrand, W F 1980. Cyclic and static laboratory tests on Drammen clay, Jnl. Geotech. Eng. 106(5): 499-529.

3 Arnold, C and Reitherman, R 1982. Building Configuration and Seismic Design. Wiley-Interscience.

4 Beresnev, I A, and Kuo-Liang Wen, and Yeong Tein Yeh 1995. Nonlinear soil amplification: Its corroboration in Taiwan, Bull. Seis. Soc. Amer. 85(2): 496-515.

5 Borcherdt, R D 1994. Estimates of site-dependent response spectra for design, Earthquake Spectra 10(4): 617-653.

6 Borja, R I, Wu, W H and Smith, H A 1993. Nonlinear response of vertically oscillating rigid foundations, $\mathrm{Jnl}$. Geotech. Eng. 119(5): 893-911.

7 Borja, R I, Wen-Hwa, W, Amies, A P and Smith, H A 1994. Nonlinear lateral, rocking and torsional vibration of rigid foundations, Jnl. Geotech. Eng. 120(3): 491-513.

8 Brown, D A and Chine-Feng Shie 1990. Three dimensional finite element model of laterally loaded piles, Computers and Geotechnics 10(1): 59-79.

9 Brown, D. A., Reese, L. C. and O'Neill, M. W. 1987 Cyclic lateral loading of a large scale pile group, $\mathrm{Jnl}$. Geotech. Eng., 113(11): 1326-1343.

10 Brown, D. A., Morrison, C. and Reese, L. C. 1988 Lateral load behaviour of pile group in sand, Jnl. Geotech. Eng., 114(11): 1261-1276.

11 Byrne, P M and McIntyre J 1994. Deformations in granular soils due to cyclic loading, Proc. Settlement '94, ASCE Geotechnical Special Publication No. 40, Vol. 2, pp. 1864-1896.

12 CEN (European Committee for Standardisation) 1993. Basis for Design and Actions on Structures EUROCODE 1, Draft March (1993).

13 CEN (European Committee for Standardisation) 1993. Structures in Seismic Regions - Design, Part 5. 
Foundations, Retaining Structures and Geotechnical Aspects. EUROCODE 8, Draft September (1993).

14 Chaney, R C and Pamukcu, P E 1991. Earthquake effects on soil-foundation systems, Part II, in In: Foundation Engineering Handbook 2nd edition, edited by Hsai-Yang Fang, Van Nostrand Reinhold, Chapter 16, pp. 623-672.

15 Ciampoli, M and Pinto, P E 1994. Effects of soilstructure interaction on the inelastic response of structures In Seismic Design and Retrofitting of Reinforced Concrete Bridges, Proc. of the Second International Workshop, Queenstown, pp. 307-318.

16 Clarke, B G 1995. Pressuremeters in Geotechnical Design. Blackie Academic \& Professional.

17 Clough, R W and Penzien, J 1993. Dynamics of Structures. 2nd edition, Wiley.

18 Crouse, C B, Kramer, S L, Mitchell, R and Hushmand, B 1993. Dynamic tests of pipe pile in saturated peat, Jnl. Geotech. Eng. 119(10): 1550-1567.

19 Davis, E H and Poulos, H G 1972. Rate of settlement under two- and three-dimensional conditions, Geotechnique 22(1): 95-114.

20 Dobry, R 1994. Foundation deformation during earthquakes, Proc. Settlement '94, ASCE Geotechnical Special Publication No. 40, Vol. 2, pp. 1846-1863.

21 Duncan, J M, Evans, L T and Ooi, P S K 1994. Lateral load analysis of single piles and drilled shafts, Jnl. Geotech. Eng. 120(6): 1018-1033.

22 Fukutake, K, Ohtsuki, A, Sato, M and Shamoto, Y 1990. Analysis of saturated dense sand-structure system and comparison with the results from shaking table test, Earthquake Engineering and Structural Dynamics, 19: 977992.

23 Fussell, A 1994. Kinematic response of end bearing piles in layered soil. ME thesis, Department of Civil and Resource Engineering, University of Auckland.

24 Gazetas, G 1991. Foundation vibrations, In: Foundation Engineering Handbook 2nd edition, edited by Hsai-Yang Fang, Van Nostrand Reinhold, Chapter 15, pp. 537-593.

25 Gazetas, G, Dakoulas, P and Papageorgiou, A 1990. Local soil and source mechanicsm effects in the 1986 Kalamata (Greece) earthquake, Earthquake Engineering and Structural Dynamics, 19: 431-456.

26 Ghahramani, A and Berrill, J B 1995. Seismic bearing capacity factors for clay soils by zero extension line method, Proc. Annual Technical Conference, NZNSEQE, pp. 167-174.

27 Girault, P 1986. Analyses of foundation failures, Proc. Int. Conf. Sponsored by the Mexico section of the ASCE: The Mexico Earthquakes 1985 - Factors Involved and Lessons Learned, Mexico City, pp. 178-192.

28 Gupta, A. K. 1990. Response Spectrum Method in seismic analysis and design of structures. Blackwell Scientific, Cambridge, Massachusetts.
29 Hatakana, M, Suzuki, Y, Kawasaki, T and Endo, $M$ 1989. Dynamic properties of undisturbed Tokyo gravel, Proc. Discussion Session on Influence of Local Soil Conditions on Seismic Response, 12 th. ICSMFE, Rio de Janeiro, pp. 107-112

30 Huang, W Chen, Y N and Singh, S 1980. Earthquake induced lateral earth pressure, Proc. Second ASCE Conference on Civil Engineering and Nuclear Power Vol. II, pp. $10-10-2$ - 10-10-17.

31 Hudson, M, Idriss, I M and Beikae, M 1994. QUAD4M a computer program to evaluate the seismic response of soil structures using finite element procedures incorporating a compliant base, Center for Geotechnical Modelling, Department of Civil \& Environmental Engineering, University of California, Davis.

32 Hughes, J M O 1993. Personal communication.

33 Hyodo, M, Yasuhara, K and Murata, H 1988. Earthquake settlement of clays, Proc. 9th World Conference on Earthquake Engineering, Tokyo-Kyoto, Vol. III, pp. III89 - III-94.

34 Idriss, I M 1990. Response of soft soil sites during earthquakes, Proc. H B Seed Memorial Symposium, Berkeley, pp. 273-289.

35 International Conference of Building Officials. 1991. Uniform Building Code. Whittier, California.

36 Ishihara, K, Tatsuoka, F and Yasuda, S 1975. Undrained deformation and liquefaction of sand under cyclic stresses, Soils and Foundations 15(1): 29-44.

37 Ishihara, K 1985. Stability of natural deposits during earthquakes Proc. 11th ICSMFE, San Francisco, Vol. I, pp. 321-376.

38 Iwasaki, Y 1994. Decrease of shear wave velocity observed by strong ground motions at Ashigara Valley experiment site, Japan. In: Performance of Ground and Soil Structures during Earthquakes, 13th ICSMFE New Delhi, pp. 131-138.

39 Jaime, A, Rome, M P, and Resendiz, D 1990. Behaviour of friction piles in Mexico City clay, Jnl. Geotech. Eng. 116(6): 915-931.

40 Jennings, P C and Bielak, J 1973. Dynamics of buildingsoil interaction, Bull. Seis. Soc. Amer. 63(1):9-48.

41 Kagawa, T 1992. Effects of liquefaction on lateral pile response, in: Piles Under Dynamic Loads, ASCE Geotechnical Special Publication No. 34, pp. 207-223.

42 Kanai, K 1983. Engineering Seismology. University of Tokyo.

43 Kobayashi, K, Yao, S and Yoshida, N 1991. Dynamic compliance of pile group considering nonlinear behaviour around piles, Proc. 2nd. Int. Conf. on Recent Advances in Geotechnical Earthquake Engineering and Soil Dynamics, St Louis, Missouri, pp. 785-??? 
44 Kokusho, T 1987. In situ dynamic soil properties and their evaluations, Proc. 8th Asian Regional Conference on Soil Mechanics and Foundation Engineering, Kyoto, Vol. 2, pp. 215-240.

45 Kulhawy, F W and Mayne, P W 1990. Manual for estimating soil properties for foundation design, Research Report EL-6800, Geotechnical Engineering Group, Civil Engineering Department, Cornell University (Report prepared for Electric Power Research Institute, Palo Alto, California).

46 Ladd, R S, Dobry, R, Dutko, P, Yokel, R Y, and Chung, $R$ M 1989. Pore pressure buildup in clean sands because of cyclic loading, ASTM Geotechnical Testing Journal, 12(1): 77-86.

47 Lam, I P and Cheang, L 1995. Dynamic soil-pile interaction behaviour in submerged sands, $A S C E$ Convention, San Diego.

48 Larkin, T J and Marks, S 1994. The seismic analysis of sandy soils, Bulletin of the NZ National Society for Earthquake Engineering 27(2): 114-123.

49 Liu, L and Dobry, R 1992. Centrifuge study of shallow foundations on saturated sand during earthquakes, Proc. 4th Japan - US Workshop on Earthquake Resistant Design of Lifeline Facilities and Countermeasures for Soil Liquefaction, Honolulu, Vol. 1, pp. 493-508.

50 Liu, L and Dobry, R 1995. Effect of liquefaction on lateral response of piles by centrifuge model tests Bulletin of the United States National Centre for Research in Earthquake Engineering (NCEER), Buffalo, New York 9(1): 7-11.

51 Loh, Chin-Hsing, Jean Wen-Yu and Penzien, J 1994. Uniform-hazard response spectra - an alternative approach, Earthquake Engineering and Structural Dynamics 23: 433-445.

52 Long, J H and Vanneste, G 1994. Effects of cyclic lateral loads on piles in sand, Jnl. Geotech. Eng. 120(1): 225244.

53 Madabhushi, S P G and Schofield, A N 1993. Centrifuge modelling of tower structures on saturated sands subjected to earthquake perturbations, Geotechnique 43(4):555-565.

54 Marks, S., Pender, M. J., \& Larkin, T. J. 1995. Liquefaction of layered sand deposits Proc. Pacific Conference on Earthquake Engineering, Melbourne.

55 Martin, G R and Dobry, R 1994. Earthquake site response and seismic code provisions, Bulletin of the United States National Centre for Research in Earthquake Engineering (NCEER), Buffalo, New York 8(4): 1-6.

56 Matsuda, H and Ohara, S 1989. Threshold strain of clay for pore pressure buildup, In: Earthquake Geotechnical Engineering, Proc. of the Discussion Session on Influence of Local Soil Conditions on Seismic Response, 12th. ICSMFE, Rio de Janeiro, pp. 127-130.

57 McManus, K J and Turner, J P 1994. Axial capacity of broed pile foundations during earthquake loading, Proc
Annual Technical Conference NZ National Society for

Earthquake Engineering, Wairakei, pp. 69-76.

58 McVay, M, Casper, R and Shang, Te-I 1995. Lateral response of three-row groups in loose to dense sands at 3D and 5D pile spacing, Jnl. Geotech. Eng. 121(5): 436441

59 McVerry, G H 1984. Comparison of remote site and basement records as excitation of the Vogel Building, Bulletin NZ National Society of Earthquake Engineering, 17(1):3-14.

60 Mendoza, M J and Auvinet, G 1988. The Mexico City earthquake of September 19, 1985 - Behaviour of building foundations in Mexico City, Earthquake Spectra 4(4): 835-853.

61 Nagataki, Y and Senoo, H 1991. Earthquake resistant piles reinforced with ground walls, Proc. 2nd. Int. Conf. on Recent Advances in Geotechnical Earthquake Engineering and Soil Dynamics, St Louis, Missouri, pp. 793-796.

62 Negussy, D and Islam, M S 1994. Uniqueness of the steady state and liquefaction potential, Can. Geotech. Jnl. 31(1): 132-139.

63 Negussy, D, Wijewickreme, W K D and Vaid, Y P 1988 Constant volume friction of granular materials, Can. Geotech. Jnl. 25(1): 50-55.

64 Nomura, S, Shamoto, Y and Tokimatsu, K 1991. Soilpile-structure interaction during liquefaction, Proc. 2nd. Int. Conf. on Recent Advances in Geotechnical Earthquake Engineering and Soil Dynamics, St Louis, Missouri, pp. 743-750.

65 Norris, G M 1994. Seismic bridge pile foundations, Proc. Int. Conf. on Design and Construction of Deep Foundations, US Federal Highway Administration (FHWA), Orlando, Vol. 1, pp. 27-136.

66 Ogasawara, M., Kikkawa, H., Saito, A. and Gose, S 1993. In-situ tests of pile foundations on full scale, Proc. International Symposium on: Limit State Design in Geotechnical Engineering, Copenhagen, Vol. 2, pp. 341349

67 Ohsaki, Y 1969. The effects of local soil conditions upon earthquake damage, Proc. Specialty Session 2 7th ICSMFE, Mexico City, pp. 3-32.

68 Ohta, H and Nishihara, A 1991. Parameter determination for soft clay foundations Proc. Int. Conf. Geotechnical Engineering for Coastal Development (Geo-Coast '91), Yokohama; Vol. 1, pp. 51-56.

69 Ooi, P S K and Duncan, J M 1994. Lateral load analysis of groups of piles and drilled shafts, Jnl. Geotech. Eng. 120(6): 1034-1050.

70 Oweis, I S 1981. Evaluating pile performance during earthquakes, Jnl. Geotech. Eng., 107(GT5): 678-683.

71 Pak, R Y S and Guzina, B B 1995. Dynamic characterisation of vertically loaded foundations on 
granular soils, Jnl. Geotech. Eng. 121(3): 274-286.

72 Paulay, T and Priestley, M J N 1992. Seismic Design of Reinforced Concrete and Masonry Buildings, Chap. 9: Foundation Structures. Wiley Interscience

73 Peck, R B 1969. Advantages and limitations of the observational method in applied soil mechanics, Geotechnique 19(2):171-187.

74 Pecker, A and Salencon, J 1991. Seismic bearing capacity of shallow foundations on clay soils, CENAPRED, Proc. International Workshop on Seismology and Earthquake Engineering, Mexico, pp. 287-304

75 Pender, M.J. 1987. Nonlinear cyclic soil-structure interaction, Proc. Pacific Earthquake Conference, Wairakei, Vol.3 pp 83-93

76 Pender, M J 1992. Linear and nonlinear earthquake site response, Proc. Wroth Memorial Symposium, Oxford, Thomas Telford, pp. 406-419.

77 Pender, M J 1993. Aseismic pile foundation design analysis, Bulletin of the NZ National Society for Earthquake Engineering 26(1): 49-161.

78 Pender, M. J. 1994. Components of the stiffness of pile-raft foundations, Proc. XIII International Conference on Soil Mechanics and Foundation Engineering, New Delhi, Vol. 2, pp. $923-928$.

79 Pender, M. J. 1994. Earthquake response of structures on pile group foundations, Proc. 1st ROC - NZ Workshop on Earthquake Engineering, Taiwan, May, Huei-Tsyr Chen editor, Taiwanese National Centre for Research on Earthquake Engineering, pp. 32 - 50.

80 Penzien, J 1970. Soil-pile foundation interaction. In: Earthquake Engineering, edited by R L Weigel, Prentice Hall, pp. 349-381.

81 Poulos, H G and Davis E H 1980. Pile Foundation Analysis and Design, Wiley.

82 Poulos, H G 1991. Relationship between local soil conditions and structural damage in the 1989 Newcastle earthquake, I E Aust. Civil Engineering Transactions CE33(3): 181-188.

83 Pranjoto, S and Pender, M J. 1995. Gapping effects during the cyclic lateral loading of piles, Proc. Annual Technical Conference NZ National Society for Earthquake Engineering, Rotorua, pp. 160 - 166.

84 Randolf, M F and Wroth, C P. 1982. Recent developments in understanding the axial capacity of piles in clay, Ground Engineering October 17-22, 24-25, 32.

85 Randolf, M F 1994. Design methods for pile groups and piled rafts. Proc. XIII International Conference on Soil Mechanics and Foundation Engineering, New Delhi, Vol. 5, pp. 61-82.

86 Sarma, S K and Iossifelis, I S. 1990. Seismic bearing capacity of shallow strip footings, Geotechnique 40(2): 265-273.
87 Scott, R F 1974. Earthquake pressures on retaining walls, Proc. 5th World Conference on Earthquake Engineering, Rome, Vol. 2, pp. 1611-1620.

88 Seed, H B. 1986. Influence of local soil conditions on ground motions and building damage during earthquakes, 8th. Nabor Carillo Lecture, presented at the XIII National Meeting of the Mexican Society for Soil Mechanics, Mazatlan, November 22, 1086.

89 Seed, R B, Dickenson, S E and Chin Man Mok 1994. Site effects on strong shaking and seismic risk: recent developments an their impact on seismic design codes and practice, Proc. Structures Congress XII, Sponsored by the Structural Division of the ASCE, edited by N. C. Baker and B. J. Goodno, Vol. 1.

90 Shi, X and Richards, R. 1995. Seismic bearing capacity with variable shear transfer, Bulletin NZ National Society for Earthquake Engineering 28(2): 153-163.

91 Shiomi, T, Sugumoto, M, Shigeno, Y and Suzuki, Y 1991. Influence of liquefaction to pile-soil-structure interaction, Proc. 2nd. Int. Conf. on Recent Advances in Geotechnical Earthquake Engineering and Soil Dynamics, St Louis, Missouri, pp. 465-472.

92 Sladen, J. A. 1992. The adhesion factor: applications and limitations, Canadian Geotechnical Journal 29: 322-326.

93 Standards Association of Australia. 1993. Minimum design loads on structures, Part 4: Earthquake Loads. AS 1170.4 , Conberra.

94 Standards Association of New Zealand. 1992. Code of practice for general structural design and design loadings for bulidings. NZS4203:1992, Wellington.

95 Stokoe, K H, Wright, S G, Bay, J A and Roesset, J M 1994. Characterisation of geotechnical sites by the SASW method, in Geophysical Characterisation of Sites (R D Woods editor), Balkema, pp 15-25.

96 Sugimura, Y 1986. Earthquake resistant design of building foundation - Introduction and commentary on Design Guide for the Building Foundation against Seismic Force, Proc. 17th. Joint US. - Japan co-operative program in Wind and Seismic effects, edited by: N. J. Raufaste, US Department of Commerce, National Bureau of Standards, pp. 168-201.

97 Sun, J I, Golesorki, R and Seed, H B 1988. Dynamic moduli and damping ratios for cohesive soils, Report No. UCB/EERC-88/15.

98 Taylor, P W 1971. The properties of soils under dynamic conditions with application to the design of foundations in seismic areas, Report No. 79, Civil Engineering Department University of Auckland.

99 Taylor, P W and Indrawan, Z 1981. A simplified method of estimating seismic pressures for cohesive soils against basement walls, Proc. Int. Conf. On Recent Advances in Geotechnical Engineering and Soil Dynamics, University of Missouri-Rolla, Vol. I, pp. 241-246.

100 Taylor, P W, Bartlett, P E and Wiessing, P R 1981. Foundation rocking under earthquake loading, Proc. $X$ 
ICSMFE, Stockholm, Vol. III, pp. 313-322.

101 Taylor, P W and Williams, R L 1979. Foundations for capacity designed structures, Bulletin NZ Nat. Soc. for Earthquake Engineering, 12(3): 101-113.

102 Technical Committee for Earthquake Geotechnical Engineering, TC4, ISSMFE. 1993. Manual for Zonation on Seismic Geotechnical Hazards, Japanese Society for Soil Mechanics and Foundation Engineering.

103 Technical Committee for Geophysical Site Characterisation, TC10, ISSMFE. 1994. Geophysical Characerisation of Sites, edited by R D Woods, Balkema.

104 Trochanis, A M, Bielak, J and Christiano, P 1991. Threedimensional nonlinear study of piles, Jour. Geotech. Eng. 117(3): 429-447.

105 Turner, J P and Kulhawy, F H 1989. Load transfer in deep foundations under repeated axial loading, In: Foundation Engineering: current principles and practices, ASCE, Vol. 1, pp. 511-525.

106 Turner, J P and Kulhawy, F H 1989. Issues in evaluating combined repeated loading of deep foundations, In: Foundation Engineering: current principles and practices, ASCE, Vol. 2, pp. 1309-1323.

107 Vaid, Y P and Thomas, J 1995. Liquefaction and post liquefaction behaviour of sand, Jour. Geotech. Eng. 121(2): 163-173.

108 Vaid, Y P and Chern, J C 1983. Cyclic and monotonic undrained response of sands, In: Advances in the Art of Testing Soils Under Cyclic Conditions, ASCE Convention, Detroit, pp. 120-147.

109 Veletsos, A S 1977. Dynamics of structure foundation systems, in: Structural and Geotechnical Mechanics, N W Newmark Volume, edited by W J Hall, Prentice Hall, pp. 333-361.

110 Veletsos, A N and Younan, A H 1994. Dynamic soil pressures on rigid vertical walls, Earthquake Engineering and Structural Dynamics 23: 275-301.

111 Veletsos, A N and Younan, A. H 1994. Dynamic soil pressures on rigid cylindrical vaults, Earthquake Engineering and Structural Dynamics 23: 645-669.

112 Wolf, J P 1985. 'Dynamic Soil-Structure Interaction. Prentice Hall.

113 Wolf, J P 1994. Foundation Vibration Analysis Using Simple Physical Models. PTR Prentice Hall.
114 Wood, J H 1993. Retaining structures and slope stability, Chapter 8, Australian earthquake engineering manual, 3rd edition, edited by H. M. Irvine and G. L. Hutchinson, TechBooks, Melbourne.

115 Yao, S anḋ Koyayashi, K 1992. Soil-pile-superstructure system in liquefaction, Piles Under Dynamic Loads, ASCE Geotechnical Special Publication No. 34, pp. 241-255.

116 Yasuhara, K 1994. Post-cyclic degradation and recovery in undrained strength of clays, in: Performance of Ground and Soil Structures during Earthquakes, Proc. of the Discussion Session on Influence of Local Soil Conditions on Seismic Response, 13th. ICSMFE, New Delhi, pp. 143-148.

117 Yoshimi, Y, Hatanaka, M and Oh-oka, H 1977. A simple method for undisturbed sampling by freezing, Proc. Specialty Session on Undisturbed Sampling, 8th. ICSMFE, Tokyo, pp. 23-28.

118 Yoshimi, Y and Tokimatsu, K 1977. Settlement of buildings on saturated sand during earthquakes, Soils and Foundations 17(1): 23-38.

119 Youd, T L 1989. Ground failure damage to buildings during earthquakes, Foundation Engineering: Current Principles and Practices ,ASCE Geotechnical Special Publication No. 22, pp. 758-770.

120 Zeevaert, L 1983. Foundation Engineering for Difficult Subsoil Conditions. Van Nostrand.

121 Zeevaert, L 1991. Seismosoil dynamics of foundations in Mexico City earthquake, September 19, 1985, Jour. Geotech. Eng.117(3): 376-428.

122 Zeng, Xiangwu 1994. Deformation of sand foundations induced by earthquakes, Proc. Settlement ' 94 - Vertical and Horizontal Deformations of Foundations and Embankments, ASCE Special Geotechnical Publication No. 40, Vol. 1, pp. 726-739.

121 Zhao, J X, McVerry, G H and Cousins, W J 1995. Horizontal responses of the Gisborne Post Office Building in two earthquakes, Proc Annual Technical Conference NZ National Society for Earthquake Engineering, Rotorua, pp. 69-76. 